\title{
A Compact Frequency Reconfigurable Antenna for LTE Mobile Handset Applications
}

\author{
Munyong Choi, ${ }^{1}$ Hyunho Wi, ${ }^{2}$ Byeonggwi Mun, ${ }^{2}$ Yonghyun Yoon, \\ Hyunwoo Lee, ${ }^{2}$ and Byungje Lee ${ }^{2}$ \\ ${ }^{1}$ Antenna Research Department, Central Research Institute, BYD Company LTD, No. 1, Baoping Road, Baolong \\ Longgang, Shenzhen 518116, China \\ ${ }^{2}$ Kwangwoon University, 447-1 Wolgye-Dong, Nowon-Gu, Seoul 139-924, Republic of Korea
}

Correspondence should be addressed to Byungje Lee; bj_lee@kw.ac.kr

Received 30 January 2015; Revised 18 May 2015; Accepted 1 June 2015

Academic Editor: Safieddin Safavi-Naeini

Copyright (C) 2015 Munyong Choi et al. This is an open access article distributed under the Creative Commons Attribution License, which permits unrestricted use, distribution, and reproduction in any medium, provided the original work is properly cited.

\begin{abstract}
A compact $\left(8 \times 62 \times 5 \mathrm{~mm}^{3} ; 2.48 \mathrm{cc}\right)$ frequency reconfigurable antenna that uses electrical switching with PIN diodes is proposed for the low frequency LTE band $(699 \mathrm{MHz}-862 \mathrm{MHz})$, high frequency LTE band (2496 MHz-2690 MHz), GSM850/900 bands $(824 \mathrm{MHz}-960 \mathrm{MHz})$, and DCS/PCS/WCDMA bands (1710 MHz-2170 MHz). The penta-band PIFA is first designed for GSM850/900/DCS/PCS/WCDMA bands by using two slits and ground pins within a limited antenna volume $\left(8 \times 54.6 \times 5 \mathrm{~mm}^{3}\right.$; $2.18 \mathrm{cc}$ ). The frequency reconfigurable antenna based on this penta-band PIFA is thus proposed to additionally cover all LTE bands. The proposed antenna has two PIN diodes with an optimal location. For State 1 (PIN diode 1: ON state, PIN diode 2: OFF state), the proposed antenna covers the low frequency LTE band, DCS/PCS/WCDMA bands, and high frequency LTE band. For State 2 (PIN diode 1: OFF state, PIN diode 2: ON state), the antenna covers the GSM850/900 bands. Simulated and measured results show that the total efficiency of the proposed antenna was greater than $40 \%$ for all operating frequency bands.
\end{abstract}

\section{Introduction}

The antenna design for modern mobile wireless communications has faced serious technical challenges as a result of the trend for mobile handset antennas to be designed smaller due to the user requirements for industrial design. Mobile handset antennas are also required to support a variety of wireless communication standards, including GSM850/900 and DCS/PCS/WCDMA. Furthermore, Long Term Evolution (LTE) has recently become a key technology for mobile wireless communication services because LTE provides greater system capacity and coverage, a reliable high peak data rate, and an improvement in the spectrum efficiency through the use of high-performance antennas. Table 1 shows the frequency spectrum allocation for mobile wireless communication services, including GSM850/900 bands (824$960 \mathrm{MHz}), \mathrm{DCS} / \mathrm{PCS} / \mathrm{WCDMA}$ bands $(1710-2170 \mathrm{MHz})$, low frequency LTE band $(699-862 \mathrm{MHz})$, and high frequency LTE band $(2496-2690 \mathrm{MHz})$. The frequency for the LTE
$12 / 13 / 17 / 20$ bands $(699-823 \mathrm{MHz})$ was recently allocated at lower frequencies than even the adjacent GSM850/900 bands, so the most important issue at this time is to design a compact mobile handset antenna for lower frequency bands that can operate within a small volume.

If all of the bands shown in Table 1 are to be considered, the mobile handset antenna is required to operate within two main bands: a low frequency (LF) band (699-960 MHz) and a high frequency (HF) band $(1710-2690 \mathrm{MHz})$. When a mobile handset antenna operates at the LF band, the impedance bandwidth that is required is of about $31.6 \%$. It is physically difficult to cover the LF band by using conventional mobile antennas within a small volume, such as with PIFA, monopole, slot, and loop antennas [1]. The most critical issue in the design of a mobile handset antenna is thus to achieve a wide impedance bandwidth in the LF band within a limited volume. In order to broaden the impedance bandwidth in lower frequency bands, the mobile handset PCB ground plane has been generally used as a radiator 
TABLE 1: Frequency spectrum allocation in mobile wireless communication services.

\begin{tabular}{|c|c|c|c|}
\hline & Band class & Uplink (MHz) & Downlink (MHz) \\
\hline \multirow{4}{*}{ GSM } & GSM 850 & $824 \sim 849$ & 869 894 \\
\hline & GSM 900 & $880 \sim 915$ & $925 \sim 960$ \\
\hline & PCS 1800 & $1710 \sim 1785$ & $1805 \sim 1880$ \\
\hline & PCS 1900 & $1850 \sim 1910$ & $1930 \sim 1990$ \\
\hline \multirow{2}{*}{ CDMA } & BC0 (850) & $824 \sim 849$ & $869 \sim 894$ \\
\hline & BC1 (1900) & $1850 \sim 1910$ & $1930 \sim 1990$ \\
\hline \multirow{4}{*}{ WCDMA } & B5 (850) & $824 \sim 849$ & $869 \sim 894$ \\
\hline & B8 (900) & $880 \sim 915$ & $925 \sim 960$ \\
\hline & B2 (1900) & $1850 \sim 1910$ & $1930 \sim 1990$ \\
\hline & $\mathrm{B} 1(2100)$ & $1920 \sim 1980$ & $2110 \sim 2170$ \\
\hline \multirow{2}{*}{ LTE (TDD) } & B38 & $2570 \sim 2620$ & $2570 \sim 2620$ \\
\hline & B41 & $2496 \sim 2690$ & $2496 \sim 2690$ \\
\hline \multirow{12}{*}{ LTE (FDD) } & B1 & 1920 1980 & $2110 \sim 2170$ \\
\hline & B2 & $1850 \sim 1910$ & $1930 \sim 1990$ \\
\hline & B3 & $1710 \sim 1785$ & $1805 \sim 1880$ \\
\hline & B4 & $1710 \sim 1755$ & $2110 \sim 2155$ \\
\hline & B5 & $824 \sim 849$ & $869 \sim 894$ \\
\hline & B7 & $2500 \sim 2570$ & $2620 \sim 2690$ \\
\hline & B8 & $880 \sim 915$ & $925 \sim 960$ \\
\hline & B12 & $699 \sim 716$ & 729 746 \\
\hline & B13 & $778 \sim 787$ & $746 \sim 756$ \\
\hline & B17 & $704 \sim 716$ & $734 \sim 746$ \\
\hline & B20 & $823 \sim 862$ & $791 \sim 821$ \\
\hline & B25 & $1850 \sim 1915$ & 1930 1995 \\
\hline
\end{tabular}

since the antenna itself and the ground plane can be treated as two arms of a half-wavelength dipole antenna at around GSM850/900 bands (824-960 MHz) [2]. In the low frequency LTE band (699-862 MHz), the length of the ground plane of the mobile handset is nevertheless small in terms of its wavelength, so it is not possible for it to act as one arm of a half-wavelength dipole antenna. As a result, various antenna design techniques have been studied to achieve wideband and multiband capabilities while maintaining a compact antenna volume [3-6]. In addition, parasitic elements or branches in conjunction with a PIFA or monopole antenna have been studied to obtain a wider impedance bandwidth and multiband operation [3]. The ground plane has also been modified by inserting slots or slits to improve its impedance bandwidth [5, 6]. A combination of multiple resonant modes such as PIFA and slot, PIFA and loop, monopole and loop, and wideband or multiband operation can be obtained within a compact volume for mobile handset antennas [4]. However, most prior studies have not been able to cover the entire range of commercial mobile communication service bands, including all LTE bands. Although one of the designed antennas may cover all of the required impedance bandwidth (699$960 \mathrm{MHz}$ and $1710-2690 \mathrm{MHz}$ ), such an antenna occupies a large volume and is difficult to implement for various mobile handsets because it has critical limitations when considering constraints in terms of the suitability for mass production, complexity of the circuit, and a high manufacturing cost.
Fortunately, simultaneous operation is not required in all service bands for mobile wireless communications. This means that the operating frequency of an antenna can be changed at any given time to operate within a required subset of the total number of bands. Therefore, frequency reconfigurable antennas have received a significant amount of attention due to their applicability for mobile wireless communications. Their properties have been adapted to achieve selectivity in frequency, bandwidth, polarization, and gain, which can result in a significant reduction in the overall size of the multimode, multiband wireless communication systems and can replace multiple single-function legacy antennas. Frequency reconfigurable antennas have also been studied by using several techniques with varactor diodes, microelectromechanical system (MEMS) switches [7], and PIN diodes [8, 9]. However, varactor diodes exhibit a voltage dependent capacitance and are sensitive not only to an externally supplied DC voltage but also to a directly induced RF voltage. To apply MEMS switches in mobile handsets, the complexity of the circuit and the high manufacturing costs should be considered. The PIN diode switching technique is very promising for use with frequency reconfigurable technology due to its significant advantages in terms of its easy realization, simple bias circuit, and low dissipated power loss.

In this paper, penta-band PIFA with two slit antennas is first designed to cover existing 3G service bands (GSM850/ 900/DCS/PCS/WCDMA) within a compact antenna volume. Then, the frequency reconfigurable antenna is proposed to cover 3G service bands (GSM850/900 bands, $824-960 \mathrm{MHz}$; DCS/PCS/WCDMA bands, $1710-2170 \mathrm{MHz}$ ) and the entire range of LTE bands (low frequency LTE band, $699-862 \mathrm{MHz}$; high frequency LTE band, $2496-2690 \mathrm{MHz}$ ) by embedding ground pins and two PIN diodes on the optimum location of the ground plane of the penta-band PIFA while minimizing the increase in the antenna volume.

\section{Penta-Band PIFA Design}

To cover commercial 3G bands (GSM850/900/DCS/PCS/ WCDMA), the penta-band PIFA was first designed with two slits and ground pins within a limited antenna volume. Figure 1 shows overview and detailed dimensions of the proposed penta-band PIFA that is printed on the antenna supporter with two slits. The outer housing case (Epoxy SLA resin + polyacrylate; $\varepsilon_{r}=3.13, \tan \delta=0.02$ ) has dimensions of $126 \times 66 \times 8.9 \mathrm{~mm}^{3}$. The substrate (FR-4; $\left.\varepsilon_{r}=4, \tan \delta=0.02\right)$ has an overall size of $7 \times 62 \times$ $1 \mathrm{~mm}^{3}$, and the PCB ground plane has an overall size of $115 \times$ $62 \times 1 \mathrm{~mm}^{3}$, which is based on the size of a commercial smartphone. The antenna support (Epoxy SLA resin + polyacrylate; $\varepsilon_{r}=3.13, \tan \delta=0.02$ ) has a volume of $62 \times 8 \times$ $5 \mathrm{~mm}^{3}$. Figure 2 shows the simulated $S_{11}$ of the proposed penta-band PIFA. This antenna can cover the penta-band (VSWR < 3) for GSM850/900/DCS/PCS/WCDMA bands. Multiband operation and a wide bandwidth were achieved by combining the PIFA mode and two slit modes. The surface current distribution was verified to be as shown in 


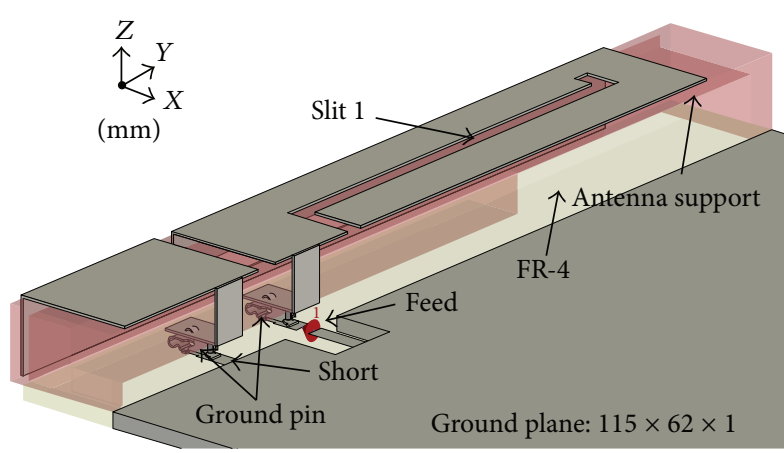

(a)

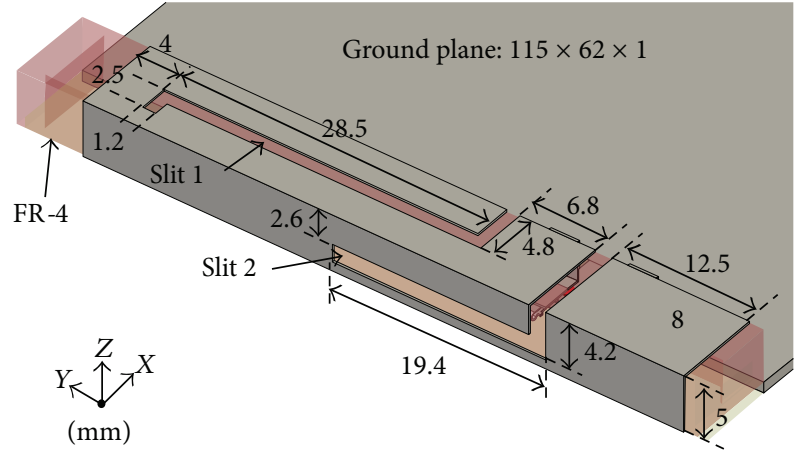

(b)

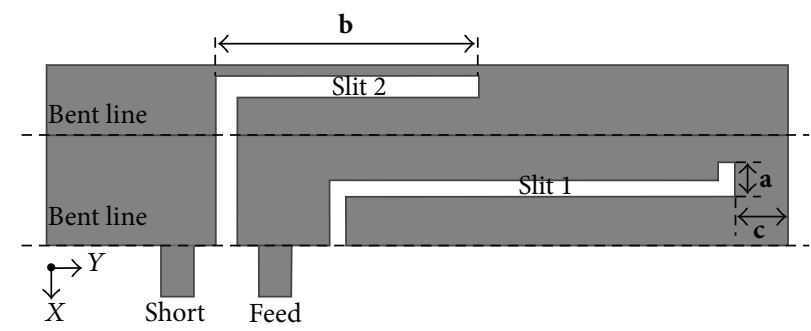

(c)

Figure 1: The geometry of the proposed penta-band PIFA: (a) overall view, (b) detailed dimensions, and (c) unfolded view of the radiating elements.

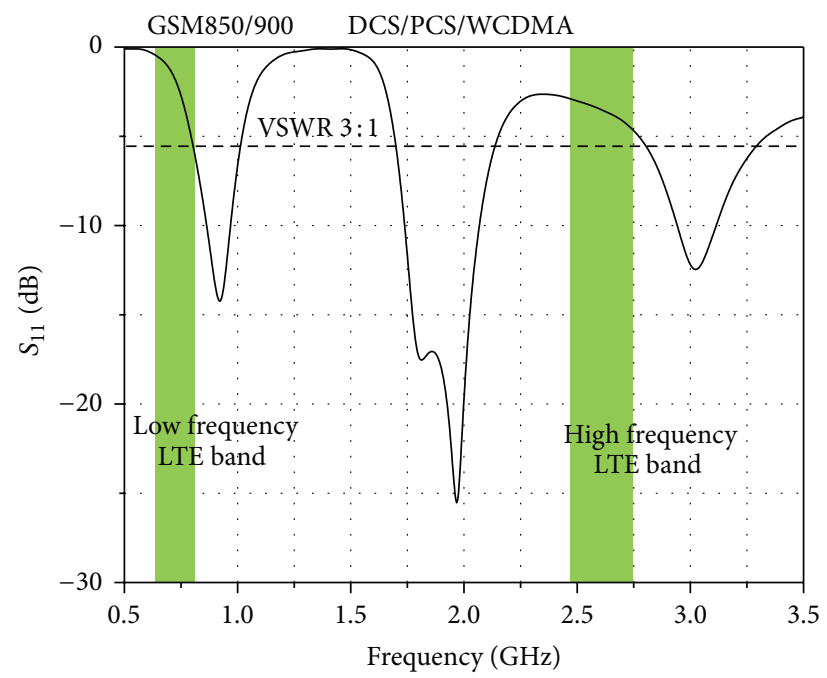

FIgURE 2: Simulated $S_{11}$ of the proposed penta-band PIFA.

Figure 3. The GSM850/900 bands are covered by the fundamental resonant mode of the PIFA as shown in Figure 3(a). DCS/PCS/WCDMA bands were covered in combination with the half-wavelength slit resonant mode for Slit 1 and Slit 2 as shown in Figures 3(b) and 3(c), respectively. The 3rd harmonic resonant mode for PIFA was achieved at around $3 \mathrm{GHz}$, as shown in Figure 3(d). Figure 4 shows the current path of each resonant mode in an unfolded view, as shown in Figure 1(c). Each resonant mode of the proposed penta-band PIFA was independently achieved at each resonant frequency. Figure 5 shows the simulated $S_{11}$ for different $\mathbf{a}, \mathbf{b}$, and $\mathbf{c}$ lengths, as shown in Figure 1(c). Figures 5(a) and 5(b) show that the impedance can be matched around $1800 \mathrm{MHz}$ and $1900 \mathrm{MHz}$ by varying the length of $\mathbf{a}$ and $\mathbf{b}$, respectively, so the DCS/PCS/WCDMA bands are easily achieved by optimally tuning the length of $\mathbf{a}$ and $\mathbf{b}$. Figure 5(c) shows that the resonant frequencies of the proposed antenna can be controlled by the length of $\mathbf{c}$. When the length for $\mathbf{c}$ increases, the resonant frequencies of the lower and higher bands move downward. Although the proposed penta-band PIFA has a wide bandwidth and multiband operation within a compact volume, the low frequency LTE band and the high frequency LTE band are not covered, as shown in Figure 2. In order to cover the entire LTE frequency band, an additional 


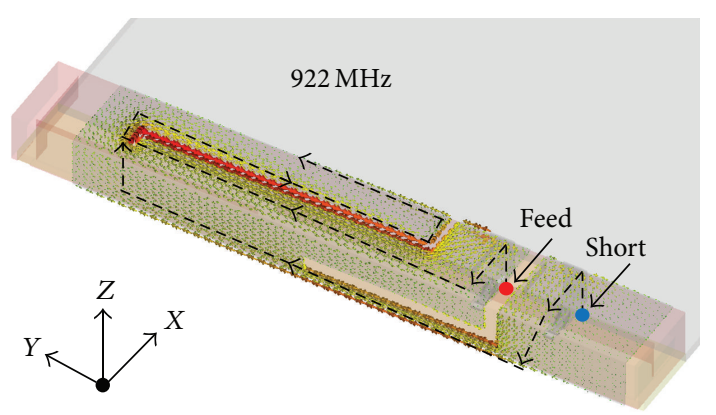

(a)

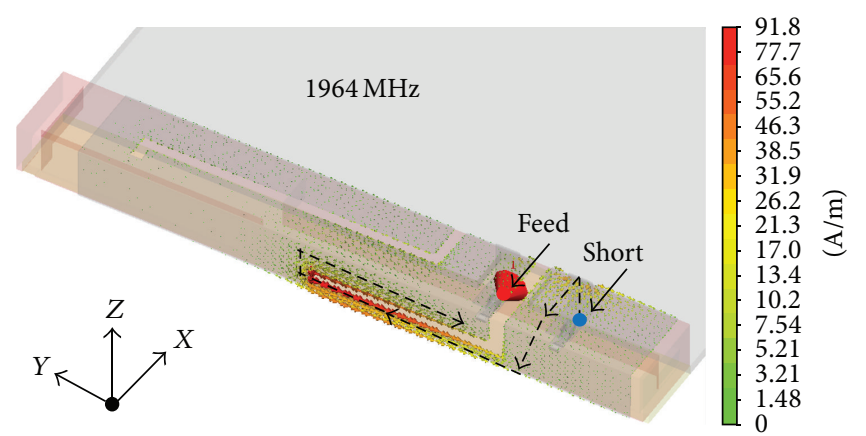

(c)
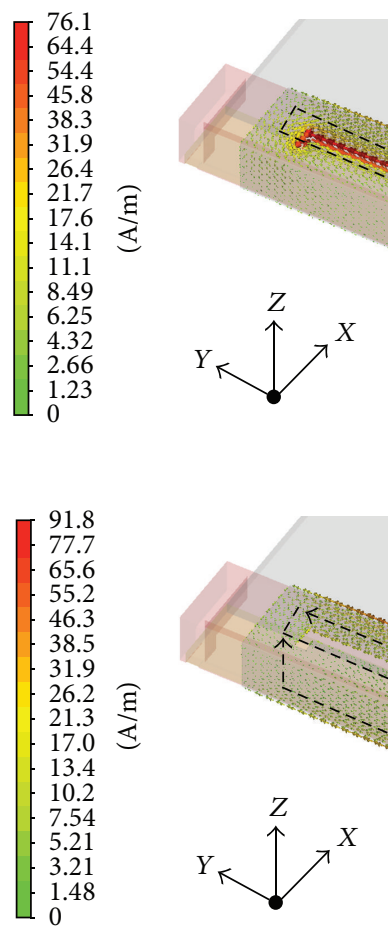

Figure 3: Simulated surface current distribution at (a) $922 \mathrm{MHz}$, (b) $1802 \mathrm{MHz}$, (c) $1964 \mathrm{MHz}$, and (d) $3026 \mathrm{MHz}$.

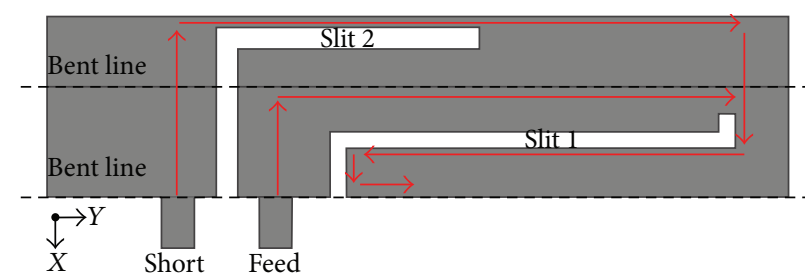

(a)

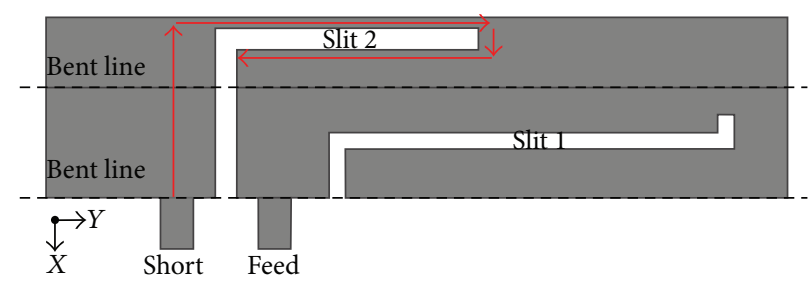

(c)

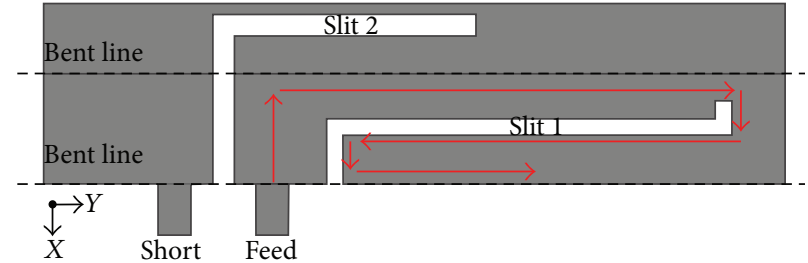

(b)

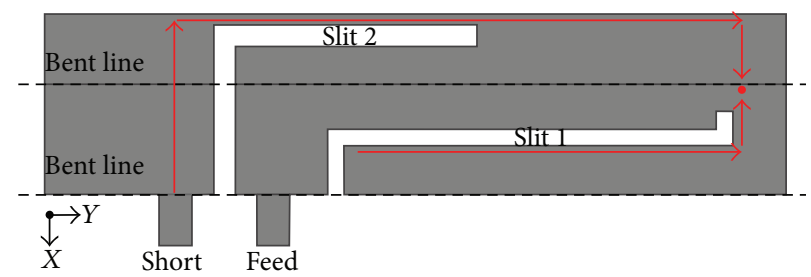

(d)

FiguRE 4: Illustration of the current distribution in an unfolded view: (a) at $922 \mathrm{MHz}$, (b) at $1802 \mathrm{MHz}$, (c) at $1964 \mathrm{MHz}$, and (d) at $3026 \mathrm{MHz}$.

resonant mode is required at the low frequency LTE band $(699-862 \mathrm{MHz})$ and the $3 \mathrm{rd}$ harmonic resonant mode of the penta-band PIFA at $3026 \mathrm{MHz}$ is needed to shift the high frequency LTE band $(2496-2690 \mathrm{MHz})$. In the next section, the frequency reconfigurable antenna in conjunction with this proposed penta-band PIFA is proposed by embedding ground pins and two PIN diodes to cover the $3 \mathrm{G}$ service bands (GSM850/900/DCS/PCS/WCDMA bands) and the entire range of LTE bands.

\section{Proposed Frequency Reconfigurable Antenna Design}

In the previous section, the penta-band PIFA is designed for the GSM850/900/DCS/PCS/WCDMA bands, and the 3rd harmonic resonant mode occurred at around $3 \mathrm{GHz}$. In order to additionally cover both the low frequency LTE band and the high frequency LTE band, the proposed penta-band PIFA is first modified with a longer $\mathbf{c}$ length and an additional ground pin, as shown in Figure 6. The length of c slightly 


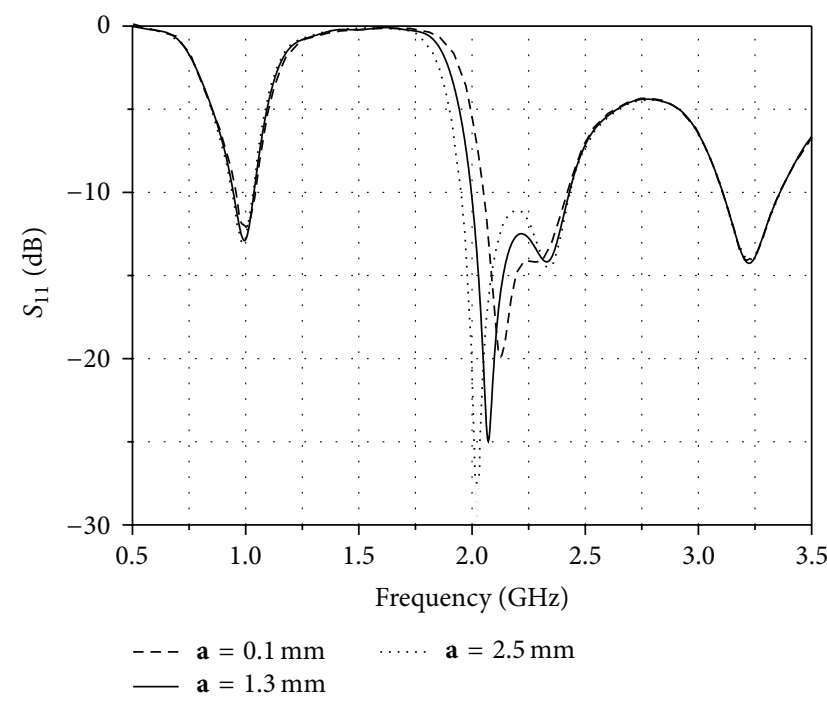

(a)

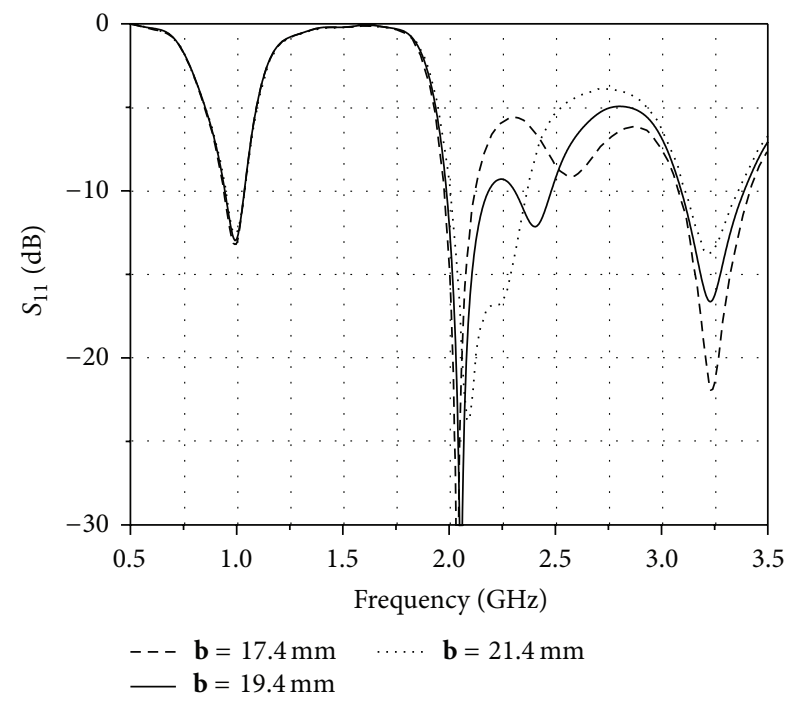

(b)

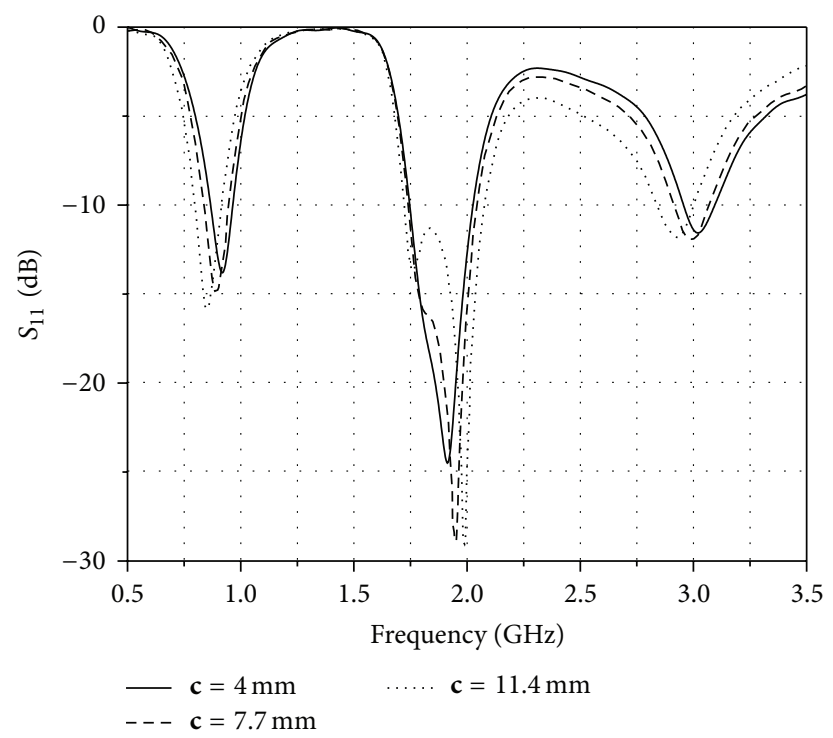

(c)

FIGURE 5: Simulated $S_{11}$ by varying the length of $\mathbf{a}, \mathbf{b}$, and $\mathbf{c}$, as shown in Figure 1(c); (a) varying the length of $\mathbf{a}, \mathbf{b}=19.4 \mathrm{~mm}$, and $\mathbf{c}=4 \mathrm{~mm}$, (b) $\mathbf{a}=2.5 \mathrm{~mm}$, varying the length of $\mathbf{b}$, and $\mathbf{c}=4 \mathrm{~mm}$, and $(\mathrm{c}) \mathbf{a}=2.5 \mathrm{~mm}, \mathbf{b}=19.4 \mathrm{~mm}$, and varying the length of $\mathbf{c}$.

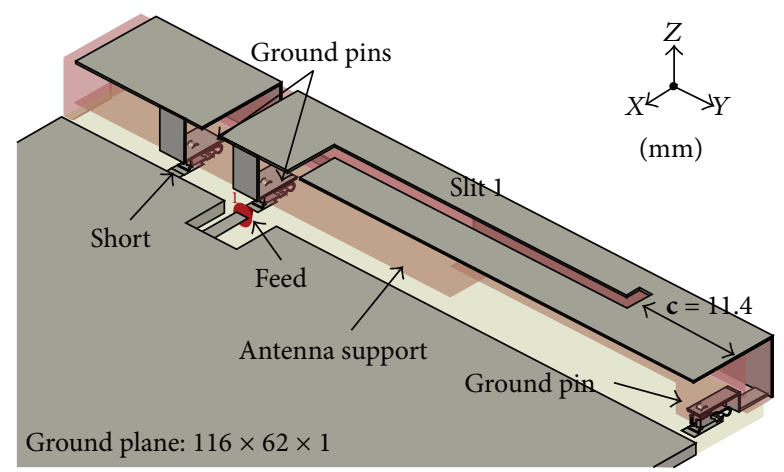

FIgURE 6: The structure of the modified penta-band PIFA. 


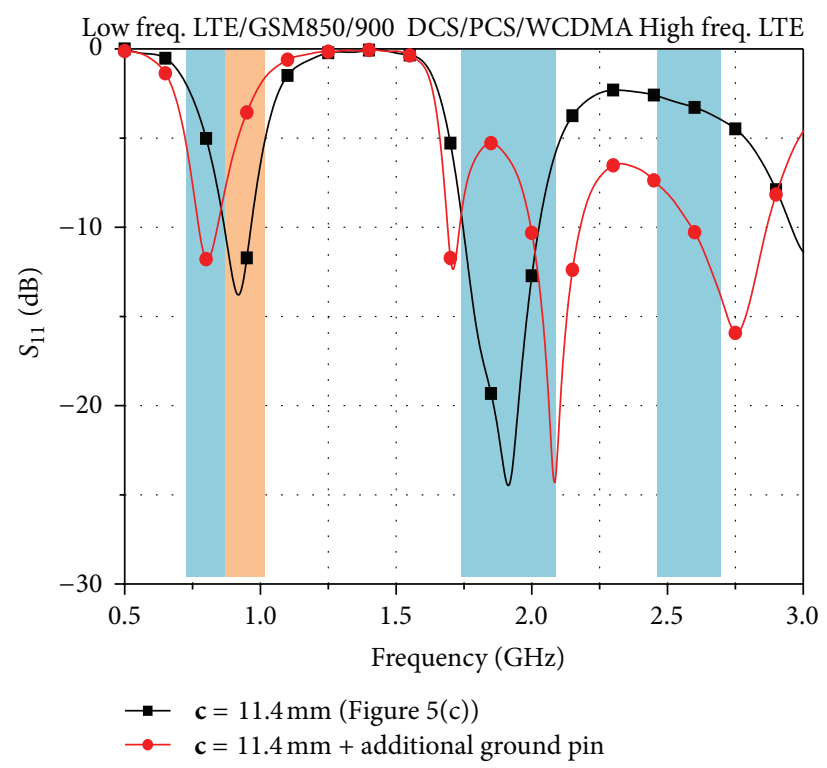

FIGURE 7: Simulated $S_{11}$ of the modified penta-band PIFA with the increased length of $\mathbf{c}=11.4 \mathrm{~mm}$ and an additional ground pin at the upper right side.

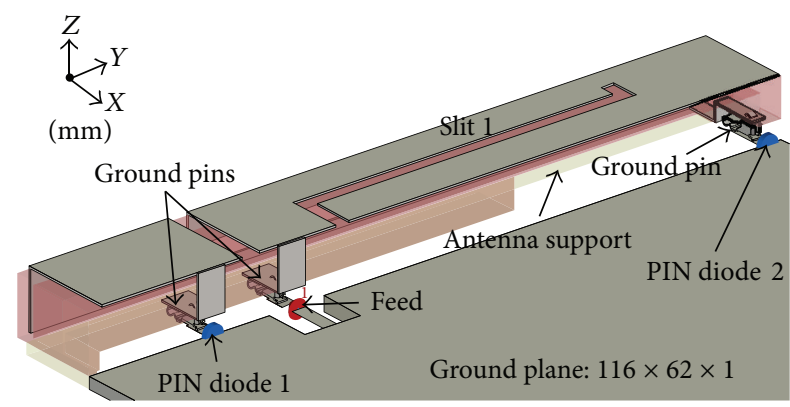

(a)

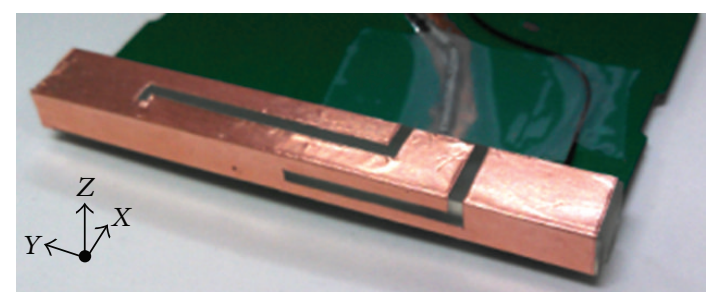

(b)

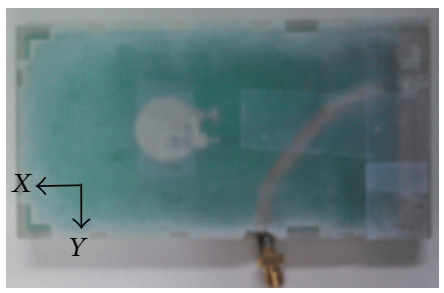

(c)

FIGURE 8: The structure of the proposed antenna: (a) overall view, (b) photograph of the proposed antenna without the outer housing case, and (c) photograph of the proposed antenna with the outer housing case.

increases to $11.4 \mathrm{~mm}$ without an increase in the antenna height and support. As shown in Figure 5(c), the resonant frequencies of the penta-band PIFA move downward as the length for $c$ increases. An additional ground pin is added at the upper right side, so the resonant frequencies of the modified penta-band PIFA further shift downward as shown in Figure 7. Then, two PIN diodes (PIN diode 1 and PIN diode 2) are finally embedded as ground pins at the upper left side and the upper right side of the proposed antenna, as shown in Figure 8(a). Figures 8(b) and 8(c) show a photograph of the proposed antenna without/with an outer housing case, respectively. Figure 9 shows the simulated $S_{11}$ of the proposed antenna with the switching technique. For State 1 (PIN diode 1: ON state, PIN diode 2: OFF state), the proposed antenna operates in the low frequency LTE band, DCS/PCS/WCDMA bands, and high frequency LTE band. It is observed that the first and the 3rd harmonic resonant modes now shift downward to cover the low frequency LTE band and the high frequency LTE band, respectively, by using the increased c length $(11.4 \mathrm{~mm})$ and an additional ground pin at the upper 


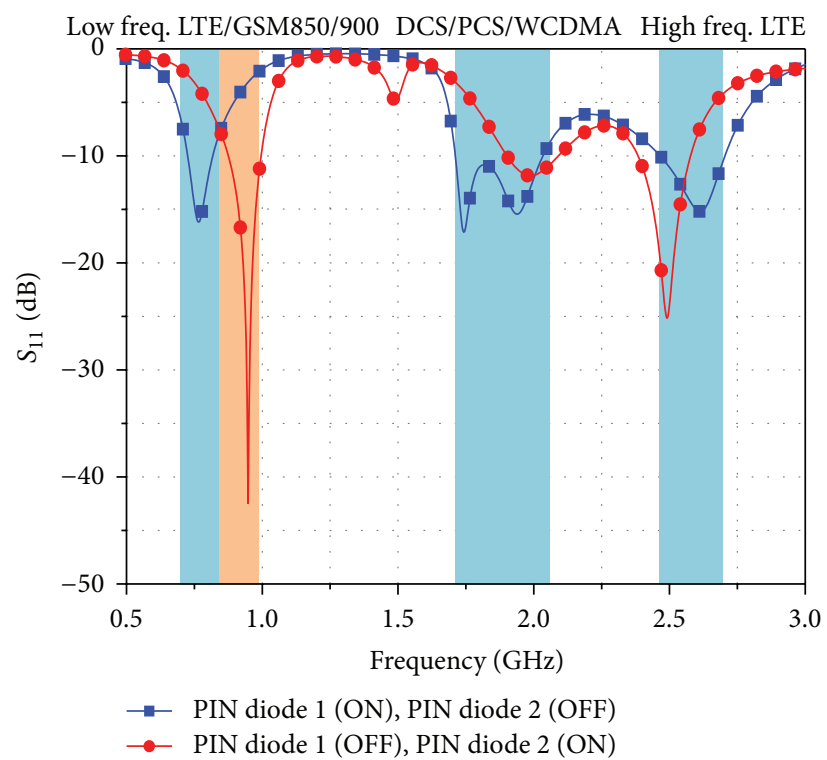

FIGURE 9: Simulated $S_{11}$ of the proposed antenna.

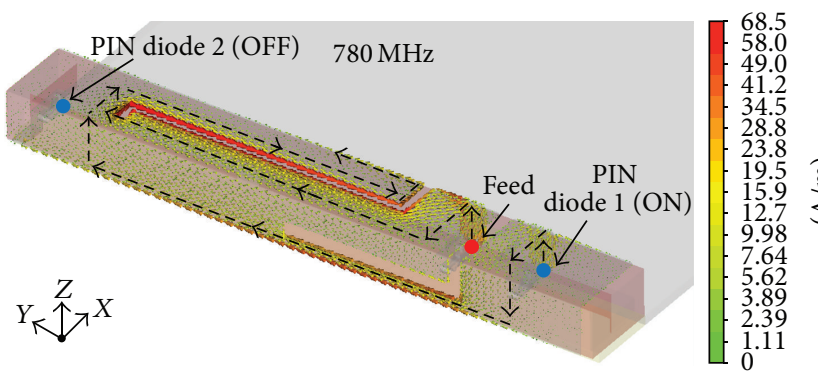

(a)
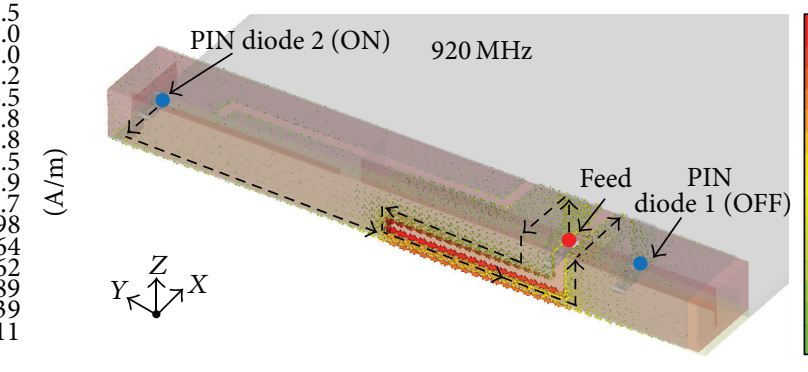

(b)

FIGURE 10: Simulated surface current distribution of the proposed antenna: (a) at $780 \mathrm{MHz}$ (State 1) and (b) at $920 \mathrm{MHz}$ (State 2).

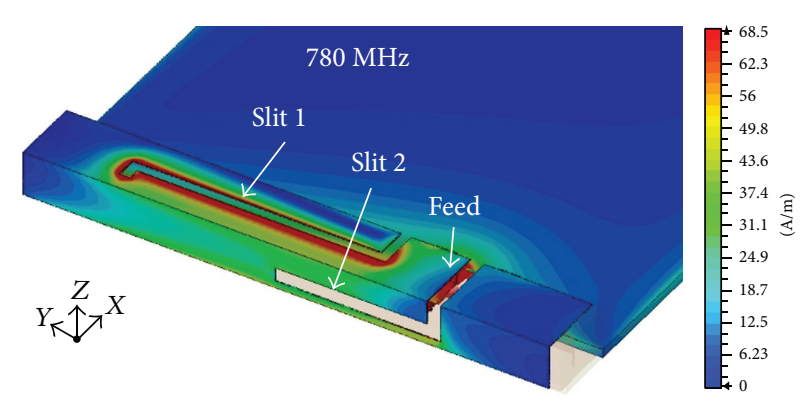

(a)

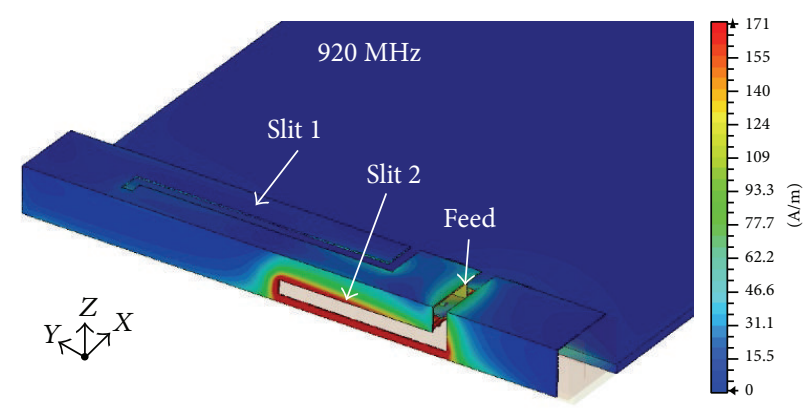

(b)

FIGURE 11: Simulated surface current distribution of the proposed antenna including the ground plane: (a) at $780 \mathrm{MHz}(\mathrm{State} 1)$ and (b) at $920 \mathrm{MHz}$ (State 2).

right side. For State 2 (PIN diode 1: OFF state, PIN diode 2: ON state), the GSM850/900 bands are operated by the resonant mode of the PIFA in which the ground pin is connected to the PIN diode 2 at upper right side. Figures 10(a) and 10(b) show the simulated surface current distribution of the proposed antenna at $780 \mathrm{MHz}$ in the low frequency
LTE band (State 1) and at $920 \mathrm{MHz}$ in the GSM850/900 bands (State 2), respectively. It is noticed that the proposed antenna operates independently at each state (State 1 or State 2). Figures 11(a) and 11(b) also show the simulated surface current distribution of the proposed antenna including the ground plane at $780 \mathrm{MHz}$ in the low frequency LTE band 


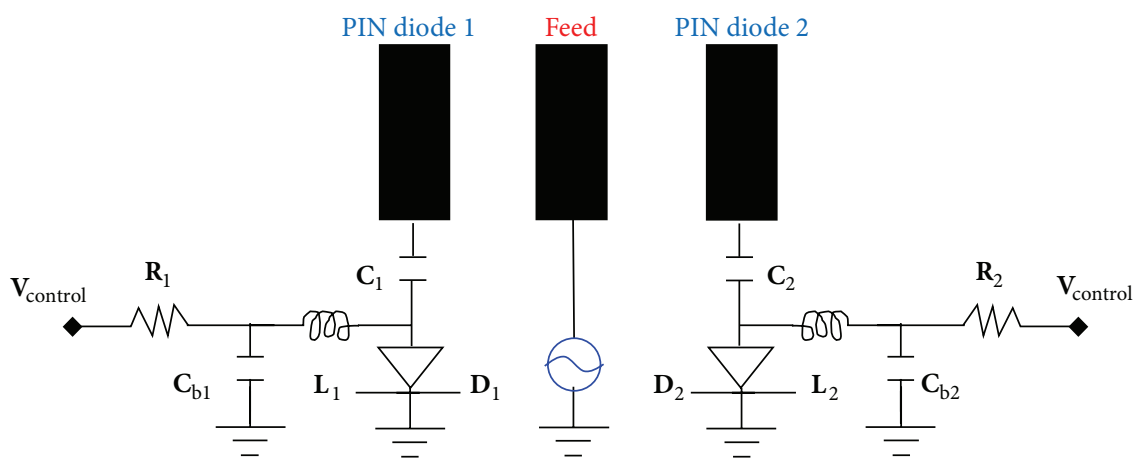

FIGURE 12: The bias circuit of the PIN diodes feed network.

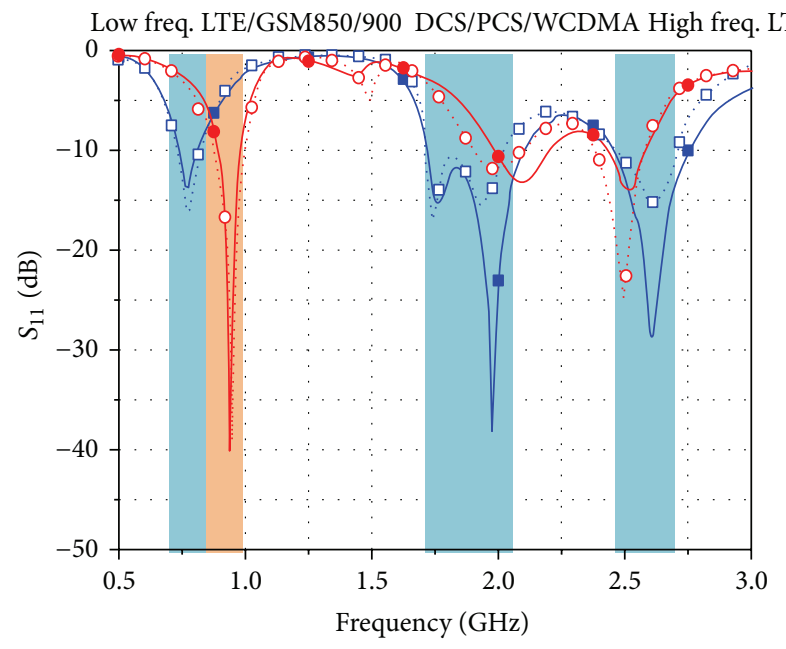

.. .. Simulated: PIN diode 1 (ON), PIN diode 2 (OFF)

$\rightarrow$ Measured: PIN diode 1 (ON), PIN diode 2 (OFF)

. o. Simulated: PIN diode 1 (OFF), PIN diode $2(\mathrm{ON})$

$\rightarrow$ Measured: PIN diode 1 (OFF), PIN diode $2(\mathrm{ON})$

(a)

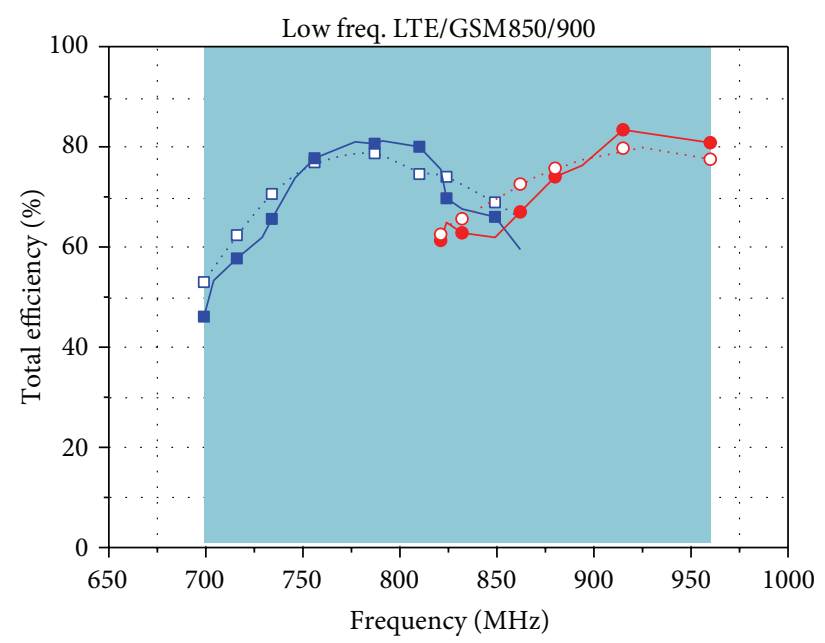

. . . Simulated: PIN diode 1 (ON), PIN diode 2 (OFF)

$\rightarrow$ Measured: PIN diode 1 (ON), PIN diode 2 (OFF)

o. Simulated: PIN diode 1 (OFF), PIN diode $2(\mathrm{ON})$

$\rightarrow$ Measured: PIN diode $1(\mathrm{OFF})$, PIN diode $2(\mathrm{ON})$

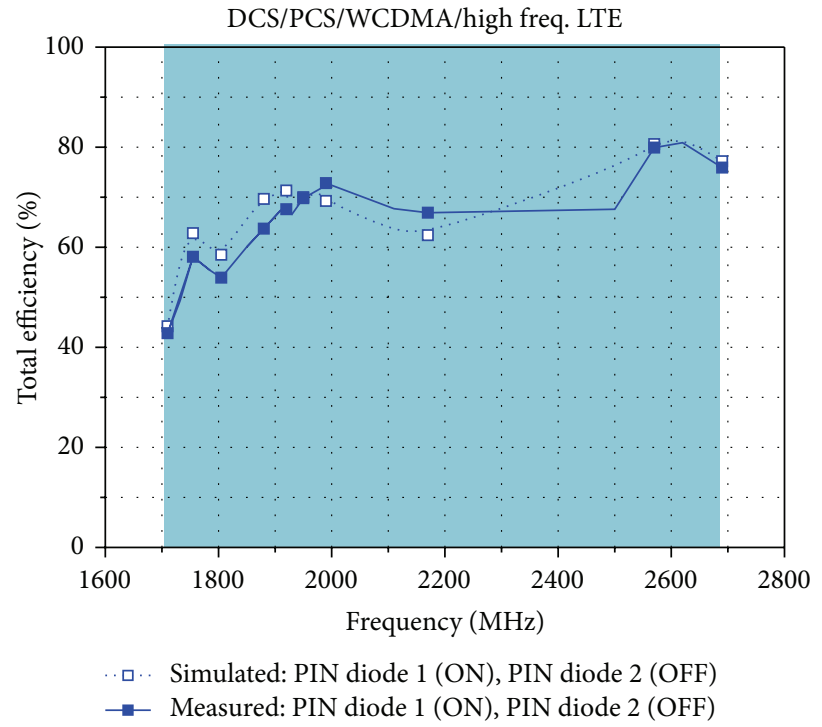

(c)

Figure 13: Simulated and measured results of the proposed antenna: (a) $S_{11}$, (b) total efficiency at the low frequency band, and (c) total efficiency at the high frequency band. 


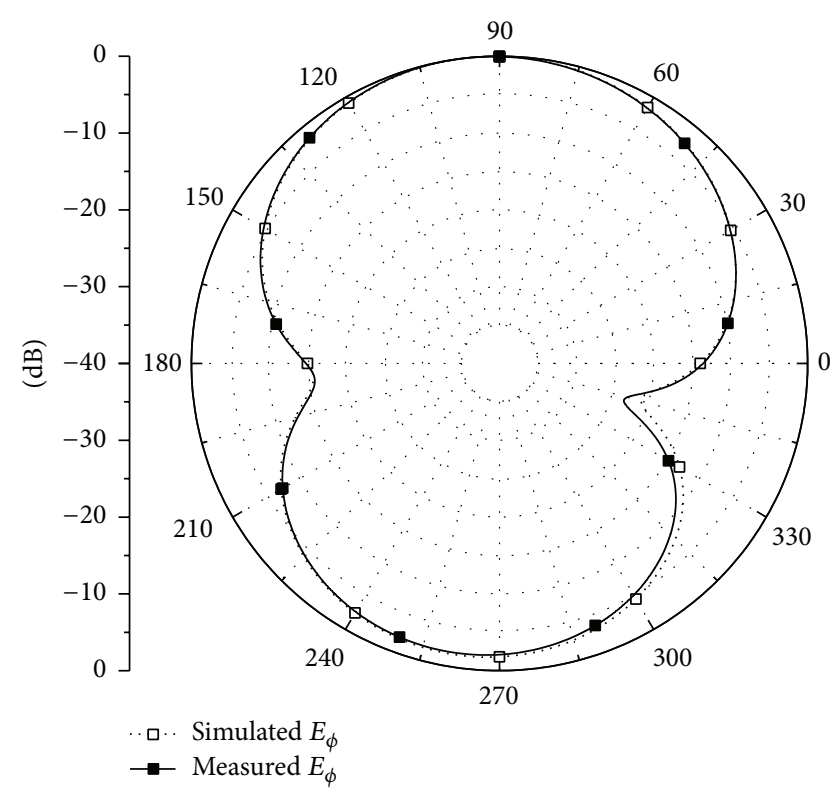

(a)

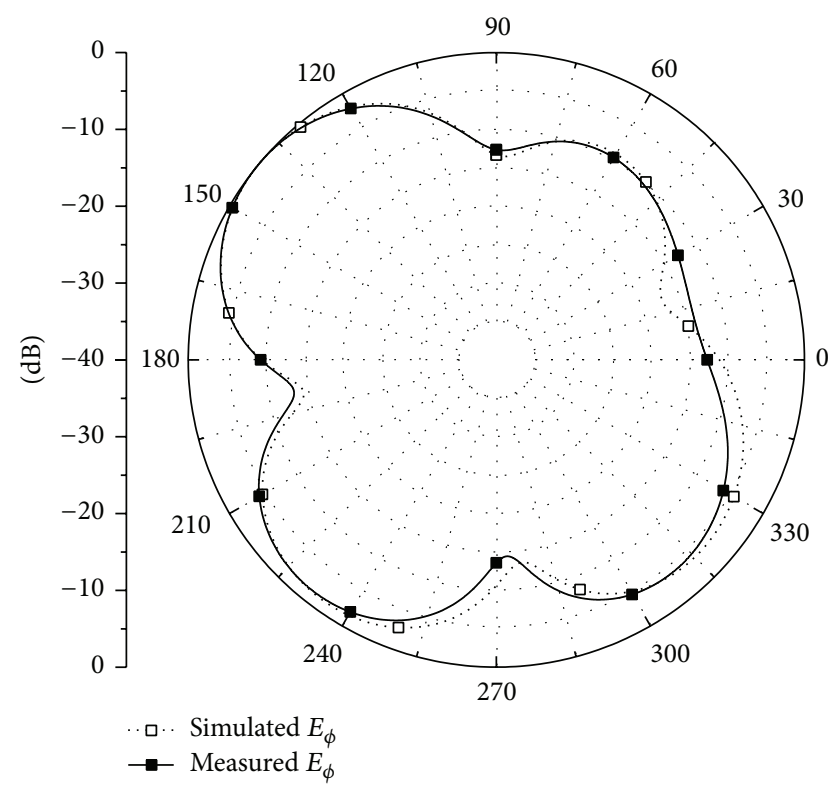

(c)

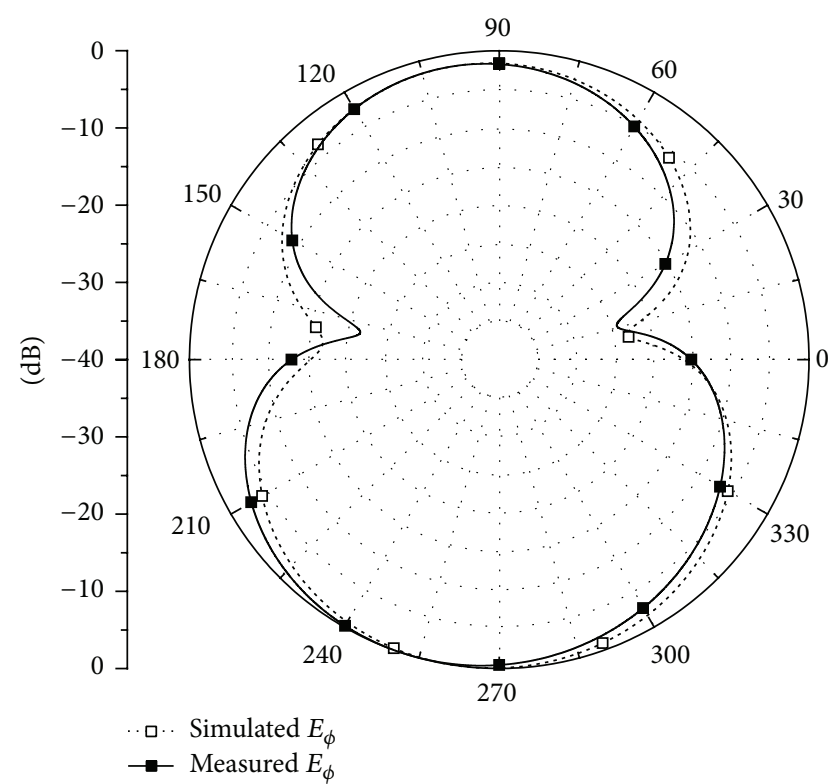

(b)

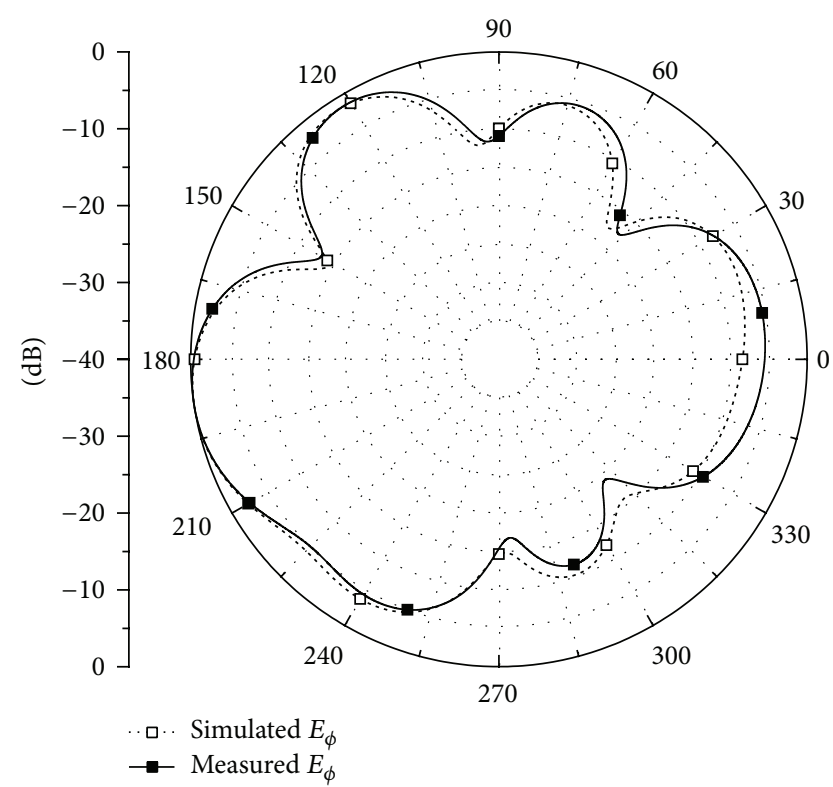

(d)

FIGURE 14: Simulated and measured radiation patterns of the proposed antenna (XY-plane): (a) $800 \mathrm{MHz}$, (b) $920 \mathrm{MHz}$, (c) $1950 \mathrm{MHz}$, and (d) $2600 \mathrm{MHz}$.

(State 1) and at $920 \mathrm{MHz}$ in the GSM850/900 bands (State 2), respectively. It is observed that the strength of the surface current on the ground plane is quite lower than that on radiators, so the radiation efficiency of the proposed antenna is not significantly affected by the user's hand effects. Increasing the length of a current path with an additional ground pin at the upper right side and combing two operation states (State 1 and State 2 ) with the switching technique, a wide impedance bandwidth at low frequency band is achieved. Therefore, the proposed antenna can effectively cover the entire range of LTE bands as well as existing commercial bands (GSM850/900/DCS/PCS/WCDMA) while conforming to a tightly constrained antenna volume. To demonstrate the validity of the proposed antenna switching scheme, the proposed antenna with two PIN diodes and bias network is designed as shown in Figure 12. The bias voltage for $\mathbf{V}_{\text {control }}$ is set to $3 \mathrm{~V}$ with a coin battery. In the bias network, the $\mathbf{R}_{1}$ and $\mathbf{R}_{2}$ resistors are used to control the bias current, the $\mathbf{C}_{1}$ and $\mathrm{C}_{2}$ capacitors are used for DC blocking, the $\mathrm{C}_{\mathrm{b} 1}$ and $\mathrm{C}_{\mathrm{b} 2}$ capacitors are used for the bypass, and the $\mathbf{L}_{1}$ and $\mathbf{L}_{2}$ inductors are used for RF choking. The values of each component in the bias network are as follows: $\mathbf{R}_{1}=\mathbf{R}_{2}=300 \Omega, \mathbf{C}_{1}=\mathbf{C}_{2}=100 \mathrm{pF}$, 
$\mathbf{C}_{\mathrm{b} 1}=\mathbf{C}_{\mathrm{b} 2}=100 \mathrm{pF}$, and $\mathrm{L}_{1}=\mathbf{L}_{2}=100 \mathrm{nH}$. The series resistance of the PIN diode has a $0.5 \Omega$ maximum at $10 \mathrm{~mA}$ in the forward biased state. SMP1322-040LF from SKYWORKS is used to minimize the dissipated power loss due to the series resistance of the PIN diode [10]. Figure 13(a) shows the simulated and measured $S_{11}$ for the proposed antenna. The simulated and the measured results are in good agreement with each other. Figures 13(b) and 13(c) show the total efficiency that was simulated and measured for the low and high frequency bands, respectively. The proposed antenna has a total efficiency greater than $40 \%$ for all operating frequency bands. The antenna efficiency is measured in an OTA chamber from HOWLAND based on CTIA 3.3 [11], which is generally acceptable for practical mobile handset antenna applications in industry [12]. Figures 14(a), 14(b), $14(\mathrm{c})$, and 14(d) show the simulated and measured radiation patterns at $800 \mathrm{MHz}, 920 \mathrm{MHz}, 1950 \mathrm{MHz}$, and $2600 \mathrm{MHz}$, respectively. The simulated and measured results agree well.

\section{Conclusion}

A compact frequency reconfigurable multiband antenna was proposed to cover most commercial 3G/4G mobile applications within a very small antenna volume of $8 \times 62 \times$ $5 \mathrm{~mm}^{3}(2.48 \mathrm{cc})$. A compact penta-band PIFA with the use of two slits and ground pins for $3 \mathrm{G}$ mobile applications was designed within a limited antenna volume $\left(8 \times 54.6 \times 5 \mathrm{~mm}^{3}\right.$; $2.18 \mathrm{cc}$ ). Then, two PIN diodes were optimally added with an additional ground pin in conjunction with the modified penta-band PIFA, and the proposed antenna can also cover the entire range of LTE bands. For State 1, the proposed antenna covers the low frequency LTE band, DCS/PCS/ WCDMA bands, and high frequency LTE band. For State 2, it covers the GSM850/900 bands. The total efficiency of the proposed antenna was greater than $40 \%$ for all operating frequency bands. The compact frequency reconfigurable antenna proposed in this paper is therefore expected to be widely applicable as a mobile handset antenna.

\section{Conflict of Interests}

The authors declare that there is no conflict of interests regarding the publication of this paper.

\section{Acknowledgments}

This research was supported by National R\&D Program through the National Research Foundation of Korea (NRF) funded by the Ministry of Science, ICT and Future Planning (2014M1A7A1A03045379) and the Research Grant of Kwangwoon University in 2015.

\section{References}

[1] Z. Ying, "Antennas in cellular phones for mobile communications," Proceedings of the IEEE, vol. 100, no. 7, pp. 2286-2296, 2012.
[2] T. Taga and K. Tsunekawa, "Performance analysis of a builtin planar inverted $\mathrm{F}$ antenna for $800 \mathrm{MHz}$ band portable radio units," IEEE Journal on Selected Areas in Communications, vol. 5, no. 5, pp. 921-929, 1987.

[3] K.-C. Lin, C.-H. Lin, and Y.-C. Lin, "Simple printed multiband antenna with novel parasitic-element design for multistandard mobile phone applications," IEEE Transactions on Antennas and Propagation, vol. 61, no. 1, pp. 488-491, 2013.

[4] H.-W. Hsieh, Y.-C. Lee, K.-K. Tiong, and J.-S. Sun, "Design of a multiband antenna for mobile handset operations," IEEE Antennas and Wireless Propagation Letters, vol. 8, pp. 200-203, 2009.

[5] A. Cabedo, J. Anguera, C. Picher, M. Ribó, and C. Puente, "Multiband handset antenna combining a PIFA, slots, and ground plane modes," IEEE Transactions on Antennas and Propagation, vol. 57, no. 9, pp. 2526-2533, 2009.

[6] J. Anguera, I. Sanz, J. Mumbrú, and C. Puente, "Multiband handset antenna with a parallel excitation of PIFA and slot radiators," IEEE Transactions on Antennas and Propagation, vol. 58, no. 2, pp. 348-356, 2010.

[7] A. C. K. Mak, C. R. Rowell, R. D. Murch, and C.-L. Mak, "Reconfigurable multiband antenna designs for wireless communication devices," IEEE Transactions on Antennas and Propagation, vol. 55, no. 7, pp. 1919-1928, 2007.

[8] Y. K. Park and Y. Sung, "A reconfigurable antenna for quad-band mobile handset applications," IEEE Transactions on Antennas and Propagation, vol. 60, no. 6, pp. 3003-3006, 2012.

[9] Y. Li, Z. Zhang, J. Zheng, Z. Feng, and M. F. Iskander, "A compact hepta-band loop-inverted $\mathrm{F}$ reconfigurable antenna for mobile phone," IEEE Transactions on Antennas and Propagation, vol. 60, no. 1, pp. 389-392, 2012.

[10] Skyworks-SMP1322-040LF, http://www.skyworksinc.com/Product.aspx?ProductID=480.

[11] CTIA, Test Plan for Wireless Device Over the Air Performance, CTIA Certification, Rev. 3.3, 2013.

[12] C. Rowell and E. Y. Lam, "Mobile-phone antenna design," IEEE Antennas and Propagation Magazine, vol. 54, no. 4, pp. 14-34, 2012. 

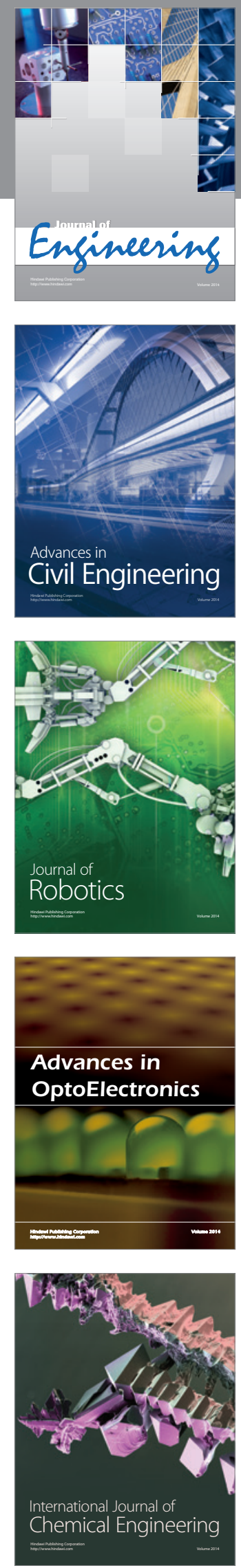

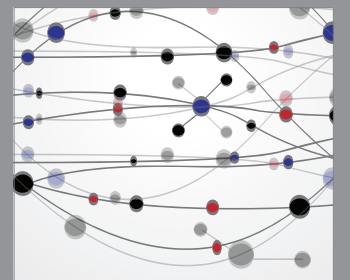

The Scientific World Journal
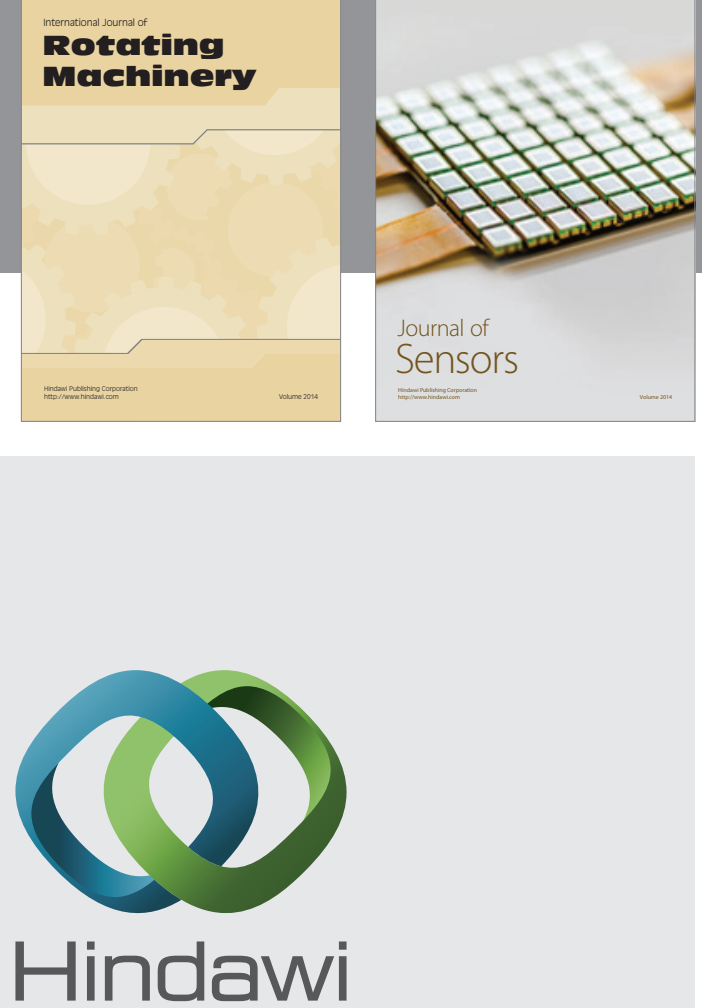

Submit your manuscripts at http://www.hindawi.com
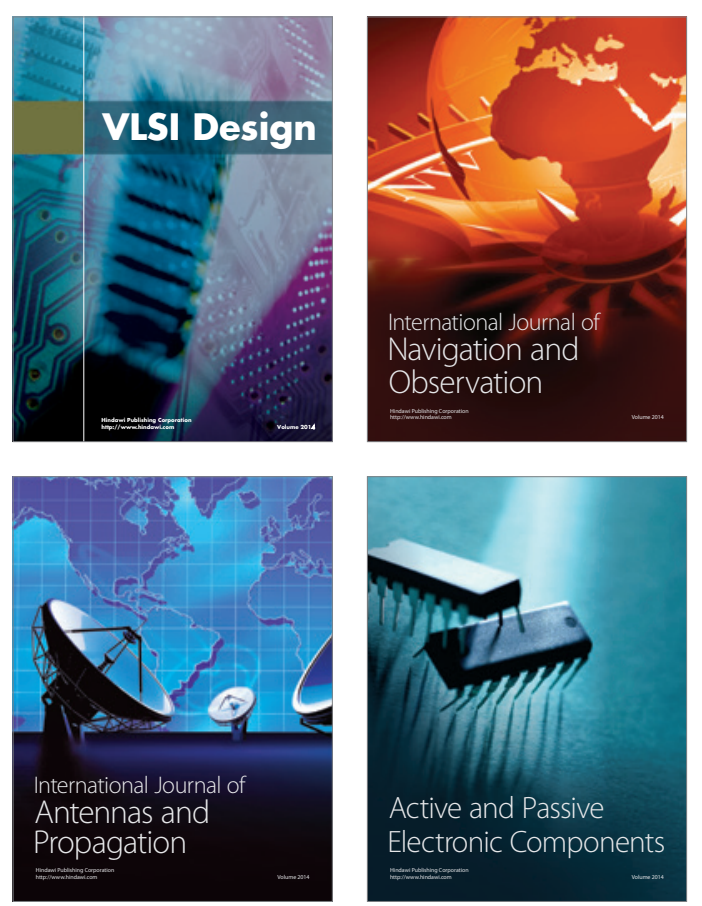
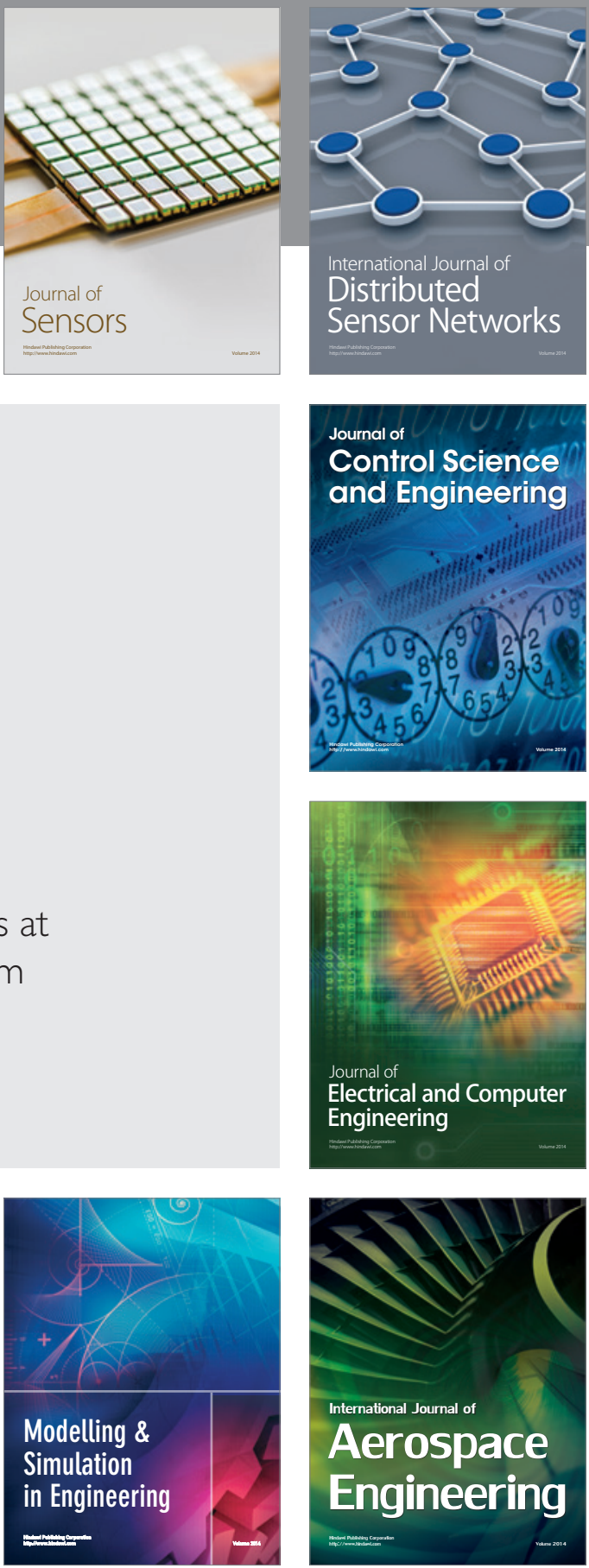

Journal of

Control Science

and Engineering
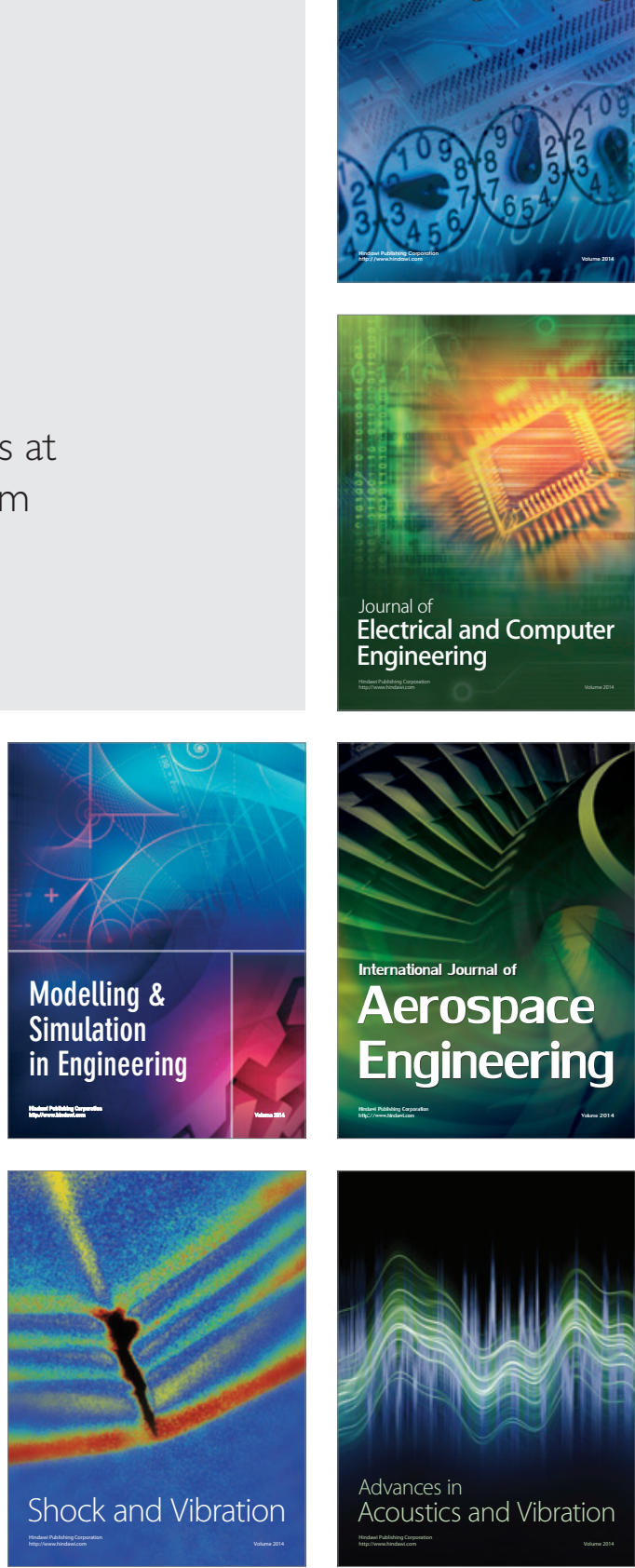